\title{
Risk of Gastrointestinal Bleeding with Rivaroxaban: A Comparative Study with Warfarin
}

\author{
Muhammed Sherid, ${ }^{1}$ Samian Sulaiman, ${ }^{2}$ Salih Samo, ${ }^{3}$ Husein Husein, ${ }^{4}$ Ruth Tupper, \\ Charles Spurr, ${ }^{1}$ Humberto Sifuentes, ${ }^{1}$ and Subbaramiah Sridhar ${ }^{1}$ \\ ${ }^{1}$ Section of Gastroenterology and Hepatology, Georgia Regents University, 1120 15th Street, AD 2226, Augusta, GA 30912, USA \\ ${ }^{2}$ Department of Internal Medicine, Froedtert Hospital and Medical College of Wisconsin, 9200 West Wisconsin Avenue, \\ Milwaukee, WI 53226, USA \\ ${ }^{3}$ Department of Medicine, Northwestern Memorial Hospital, Northwestern University Feinberg School of Medicine, 251 East Huron \\ Street, Suite 16-738, Chicago, IL 60611, USA \\ ${ }^{4}$ Department of Internal Medicine, Seton Hall University, School of Health and Medicine Sciences, Trinitas Regional Medical Center, \\ 225 Williamson Street, Elizabeth, NJ 07202, USA \\ ${ }^{5}$ Department of Internal Medicine, Saint Francis Hospital, 355 Ridge Avenue, Evanston, IL 60202, USA
}

Correspondence should be addressed to Subbaramiah Sridhar; ssridhar@gru.edu

Received 21 July 2015; Accepted 4 October 2015

Academic Editor: Gabriela Melen-Mucha

Copyright (C) 2016 Muhammed Sherid et al. This is an open access article distributed under the Creative Commons Attribution License, which permits unrestricted use, distribution, and reproduction in any medium, provided the original work is properly cited.

\begin{abstract}
Introduction. The risk of gastrointestinal (GI) bleeding with rivaroxaban has not been studied extensively. The aim of our study was to assess this risk in comparison to warfarin. Methods. We examined the medical records for patients who were started on rivaroxaban or warfarin from April 2011 to April 2013. Results. We identified 300 patients (147 on rivaroxaban versus 153 on warfarin). GI bleeding occurred in $4.8 \%$ patients with rivaroxaban when compared to $9.8 \%$ patients in warfarin group $(p=0.094)$. GI bleeding occurred in $8 \%$ with therapeutic doses of rivaroxaban $(>10 \mathrm{mg} / \mathrm{d})$ compared to $9.8 \%$ with warfarin $(p=0.65)$. Multivariate analysis showed that patients who were on rivaroxaban for $\leq 40$ days had a higher incidence of GI bleeding than those who were on it for $>40$ days $(O R$ $=2.8, p=0.023)$. Concomitant use of dual antiplatelet agents was associated with increased risk of GI bleeding in the rivaroxaban group $(\mathrm{OR}=7.4, p=0.0378)$. Prior GI bleeding was also a risk factor for GI bleeding in rivaroxaban group (OR $=15.5)$. Conclusion. The incidence of GI bleeding was similar between rivaroxaban and warfarin. The risk factors for GI bleeding with rivaroxaban were the first 40 days of taking the drug, concomitant dual antiplatelet agents, and prior GI bleeding.
\end{abstract}

\section{Introduction}

Over the last 60 years until very recently, vitamin $\mathrm{K}$ antagonists such as warfarin were the only oral anticoagulation agents available; however, due to their multiple drawbacks, the development of new oral direct factor inhibitors has emerged. Rivaroxaban is the first direct factor Xa inhibitor that has been approved by the US Food and Drug Administration (FDA) for the prevention of stroke and systemic embolism in patients with nonvalvular atrial fibrillation (AF), for the prevention and the treatment of venous thromboembolic events (VTE) [1-7]. It has also been tested for other indications [8-10]. The advantages of rivaroxaban over warfarin are numerous including a rapid onset of action, shorter half-life, no requirement for laboratory monitoring, minimal drug-drug and drug-food interactions, and minimal inter- and intraindividual variability with predictable anticoagulant effects and a fixed-dose regimen. Rivaroxaban dose varies depending on the indication and the risk of bleeding. It is administered as $10 \mathrm{mg}$ daily (prophylactic dose) for VTE prevention after major joint surgeries, whereas a dose of $15 \mathrm{mg}$ twice daily for 3 weeks followed by $20 \mathrm{mg}$ daily is the regimen for the VTE treatment [2-7]. For nonvalvular AF, it is usually given as $20 \mathrm{mg}$ daily; however a dose of $15 \mathrm{mg}$ daily is administered in patients with a high risk of bleeding as in compromised renal function (GFR: $30-49 \mathrm{~mL} / \mathrm{min} / 1.73 \mathrm{~m}^{2}$ ) $[1]$. 
Rivaroxaban selectively inhibits the active site of factor $\mathrm{Xa}$ (both free and prothrombinase-bound forms) without a requirement for cofactors such as antithrombin III [11]. The oral bioavailability of rivaroxaban is approximately $80 \%$, and the peak plasma concentration time is 1-4 hours [1217]. Rivaroxaban has a dual mode of elimination; excreted by the liver and the kidney, thus, a marked impairment of the liver or renal function may affect its pharmacokinetics and pharmacodynamics [18-20]. Elimination half-life of rivaroxaban is $7-11$ hours and extends up to 13 hours in the elderly $[12-15,17,21,22]$. It has been proven that rivaroxaban has dose-dependent anticoagulation effects over a wide range of doses [12,13]. Rivaroxaban is a substrate for P-glycoprotein and cytochrome P450 3A4; therefore, strong P-glycoprotein and cytochrome P450 3A4 inhibitors or inducers affect its pharmacokinetics and pharmacodynamics [23-25].

Despite these advantages of rivaroxaban over warfarin, the risk of bleeding, including gastrointestinal (GI) bleeding, is a concern with its use. Our hypothesis was that GI bleeding events occur more often in patients on rivaroxaban when compared to patients on warfarin. The primary aim of our study was to assess the risk of GI bleeding with rivaroxaban and compare to that of warfarin in a community hospitals setting and to identify the risk factors for developing GI bleeding in patients on rivaroxaban.

\section{Methods}

In this retrospective cohort study, we examined the medical records of all patients who were started on rivaroxaban from April 2011 to April 2013 and compared to a control group of consecutive patients who were started on warfarin during the same period in 1:1 fashion. The study was conducted in two hospitals (CGH Medical Center in Sterling, IL, and Saint Francis Hospital in Evanston, IL, USA) after obtaining the Institutional Review Board (IRB) approval from each institution. This study was conducted in collaboration with Georgia Regents University, Augusta, GA.

Demographic details, laboratory studies, information on the concomitant use of antiplatelet agents or nonsteroidal anti-inflammatory drugs (NSAIDs), duration of rivaroxaban and warfarin ( $\leq$ or $>40$ days), dose of rivaroxaban $(10 \mathrm{mg} /$ day (prophylactic dose), $>10 \mathrm{mg} /$ day (therapeutic dose)), indication for anticoagulation, GI bleeding events and the site of GI bleeding, major bleeding events and the site of bleeding, acute coronary syndrome (ACS), venous thromboembolic events (VTE), cerebrovascular events, and all-cause deaths while on an anticoagulation agent were collected. The primary aim was to assess the risk of GI bleeding in patients on rivaroxaban when compared to patients on warfarin during the study period and to identify any risk factors for developing GI bleeding. Gastrointestinal bleeding was defined as any bleeding in the GI tract that required hospitalization. The secondary aims were the risk of major bleeding events (defined as the bleeding events that required hospitalization and cessation of the anticoagulation agent), ACS that required angioplasty (with or without stenting) or heart surgery, VTE events (deep venous thrombosis or pulmonary embolism), cerebrovascular events (stroke or transient ischemic attack), and all-cause deaths while on an anticoagulation agent. Inclusion criteria were patients who were on rivaroxaban for $\geq 4$ days during the study period and were compared to age and gender-matched patients who were on warfarin for $\geq 4$ days. Exclusion criteria were an unknown duration of rivaroxaban or warfarin, lack of follow-up, age $<18$ years, pregnancy, mechanical valve replacement, and advanced kidney disease (glomerular filtration rate $(\mathrm{GFR})<$ $15 \mathrm{~mL} / \mathrm{min} / 1.73 \mathrm{~m}^{2}$ or end-stage renal disease on dialysis).

2.1. Statistical Analysis. Patients' data were entered into Microsoft Excel spreadsheet in a coded format which was locked with a password. All analyses were performed with the use of SAS software (SAS Institute Inc., Cary, NC). A 2sided $p$ value of $<0.05$ was considered statistically significant. Parametric two-sample $t$-tests were conducted to compare the means of the two groups involved, but the assumptions associated with $t$-tests (homogeneity of variances and normality of data) were not satisfied. Hence, the nonparametric Wilcoxon's rank sum test was conducted to compare the means of the two groups involved. A chi-square analysis, Fisher's exact test, and a Pearson correlation were conducted for the other variables. A logistic regression was carried out in multivariate analyses. Odds ratios (OR) were generated between group comparisons. A chi-square analysis was used for parameters in secondary aims.

\section{Results}

3.1. Patients (Table 1). A total of 300 patients were identified, of whom 147 patients were on rivaroxaban (mean age 68.3 \pm 14.5 years) and 153 patients were on warfarin (mean age $71.4 \pm 13.1$ years $)(p=0.0573)$ (Table 1$)$. Eighty-five patients $(57.82 \%)$ were $\geq 65$ years in rivaroxaban group as compared to 104 patients in warfarin group $(67.97 \%)$ $(p=0.0738)$. The majority of people in both groups were White $(76.87 \%$ versus $86.93 \%)$ and female $(52.38 \%$ versus $54.25 \%$ ) in rivaroxaban and warfarin groups, respectively. Atrial fibrillation was the indication for anticoagulation in $46.94 \%$ in rivaroxaban group versus $60.78 \%$ in warfarin group $(p<0.0001)$. Prophylactic dose $(10 \mathrm{mg} /$ day $)$ was used for VTE prophylaxis in 60 patients $(40.82 \%)$ in rivaroxaban group, whereas therapeutic doses ( $>10 \mathrm{mg} /$ day) were used in 87 patients $(59.18 \%)$. The mean duration of drug use was significantly different between rivaroxaban and warfarin groups (92.19 \pm 119.91 versus $252.95 \pm 167.91$, resp., $p<0.0001$ ) with $55.1 \%$ of patients in rivaroxaban group being on the drug for $\leq 40$ days when compared to only $10.46 \%$ of patients in warfarin group ( $p<0.0001)$. Concomitant use of aspirin, thienopyridines (clopidogrel, ticlopidine, or prasugrel), dual antiplatelet agents (aspirin and thienopyridine), and NSAIDs was found in $38.10 \%, 8.16 \%, 5.44 \%$, and $9.52 \%$, respectively, in the rivaroxaban group when compared to $41.18 \%, 17.65 \%$, $9.80 \%$, and $4.58 \%$, respectively, in the warfarin group ( $p$ values: $0.6372,0.0163,0.1558$, and 0.1144 , resp.). History of prior GI bleeding was present in 5 patients $(3.40 \%)$ in the rivaroxaban group and 15 patients $(9.80 \%)$ in the warfarin group $(p=0.0356)$. Laboratory studies $(\mathrm{Hb}<12 \mathrm{~g} / \mathrm{dL}$, creatinine $>1.5 \mathrm{mg} / \mathrm{dL}, \mathrm{GFR} \leq 30 \mathrm{~mL} / \mathrm{min} / 1.73 \mathrm{~m}^{2}$, and ALT 
TABLE 1: Demographic and clinical characteristics of patients in both groups.

\begin{tabular}{|c|c|c|c|}
\hline Patients' characteristics & $\begin{array}{c}\text { Rivaroxaban } \\
(N=147)\end{array}$ & $\begin{array}{l}\text { Warfarin } \\
(N=153)\end{array}$ & $p$ value \\
\hline Mean age \pm SD & $68.25 \pm 14.97$ & $71.35 \pm 13.09$ & 0.0573 \\
\hline Age $\geq 65$ & $85(57.82 \%)$ & $104(67.97 \%)$ & \multirow{2}{*}{0.0738} \\
\hline Age $<65$ & $62(42.18 \%)$ & $49(32.03)$ & \\
\hline \multicolumn{4}{|l|}{ Gender } \\
\hline Female & $77(52.38 \%)$ & $83(54.25 \%)$ & \multirow{2}{*}{0.8170} \\
\hline Male & $70(47.62 \%)$ & $70(45.75 \%)$ & \\
\hline \multicolumn{4}{|l|}{ Ethnic group } \\
\hline White & $113(76.87 \%)$ & $133(86.93 \%)$ & \multirow{3}{*}{$0.0221^{\dagger}$} \\
\hline AA & $14(9.52 \%)$ & $4(2.61 \%)$ & \\
\hline Others & $20(13.61)$ & $16(10.46 \%)$ & \\
\hline \multicolumn{4}{|l|}{ Indication for drug } \\
\hline $\mathrm{AF}$ & $69(46.94 \%)$ & $93(60.78 \%)$ & \multirow{4}{*}{$<0.0001^{\dagger}$} \\
\hline VTE treatment & $12(8.16 \%)$ & $56(36.60 \%)$ & \\
\hline VTE prophylaxis & $60(40.82 \%)$ & $2(1.31 \%)$ & \\
\hline Other & $6(4.08 \%)$ & $2(1.31 \%)$ & \\
\hline Low dose & $60(40.82 \%)$ & NA & \\
\hline High dose & $87(59.18 \%)$ & NA & \\
\hline Mean duration being on drug (Days) \pm SD & $92.19 \pm 119.91$ & $252.95 \pm 167.91$ & $<0.0001^{\dagger}$ \\
\hline Duration $\leq 40$ days & $81(55.10 \%)$ & $16(10.46 \%)$ & $<0.0001^{\dagger}$ \\
\hline Concomitant with aspirin & $56(38.10 \%)$ & $63(41.18 \%)$ & 0.6372 \\
\hline Concomitant with thienopyridine & $12(8.16 \%)$ & $27(17.65 \%)$ & 0.0163 \\
\hline Dual antiplatelet agents & $8(5.44 \%)$ & $15(9.80 \%)$ & 0.1558 \\
\hline Concomitant with NSAIDs & $14(9.52 \%)$ & $7(4.58 \%)$ & 0.1144 \\
\hline $\mathrm{Hb}<12$ & $55(39.29 \%)$ & $54(35.29 \%)$ & \multirow{2}{*}{0.5454} \\
\hline Missing data & 7 & 0 & \\
\hline $\mathrm{Cr}>1.5$ & $6(4.23 \%)$ & $15(9.80 \%)$ & \multirow{2}{*}{0.0714} \\
\hline Missing data & 5 & 0 & \\
\hline $\mathrm{GFR} \leq 30$ & $2(1.41 \%)$ & $6(3.92 \%)$ & \multirow{2}{*}{0.2851} \\
\hline Missing data & 5 & 0 & \\
\hline $\mathrm{ALT}>40$ & $11(9.91 \%)$ & $28(20 \%)$ & \multirow{2}{*}{$0.0349^{\dagger}$} \\
\hline Missing data & 36 & 13 & \\
\hline \multicolumn{4}{|l|}{ BMI } \\
\hline$<18.5$ & $5(3.52 \%)$ & $0(0 \%)$ & \multirow{4}{*}{0.0707} \\
\hline $18.5-24.9$ & $31(21.83 \%)$ & $35(22.88 \%)$ & \\
\hline$>25$ & $106(74.65 \%)$ & $118(77.12 \%)$ & \\
\hline Missing data & 5 & 0 & \\
\hline Previous GI bleeding & $5(3.40 \%)$ & $15(9.80 \%)$ & $0.0356^{\dagger}$ \\
\hline
\end{tabular}

AA: African American, AF: atrial fibrillation, ALT: alanine aminotransferase, BMI: body mass index, Cr: creatinine, GFR: glomerular filtration rate, GI: gastrointestinal, Hb: hemoglobin, NSIADs: nonsteroidal anti-inflammatory drugs, and VTE: venous thromboembolism events. ${ }^{\dagger}$ Signifying statistical significant values.

$>40 \mathrm{IU} / \mathrm{dL})$ and BMI $\left(<18.5,18.5-24.9, \geq 25 \mathrm{Kg} / \mathrm{m}^{2}\right)$ were not significantly different between both groups $(p>0.05$ for all parameters). We also separated the patients on therapeutic doses (>10 mg/day) of rivaroxaban from prophylactic dose group and compared them separately to the patients in warfarin group, to minimize the heterogeneity between both groups. The characteristics of patients on therapeutic doses are shown in Table 2.
Rivaroxaban was discontinued prematurely in 24 patients (16.33\%) for various reasons (GI bleeding (7), major bleeding events (6), switching to warfarin for financial issue (6), high risk for bleeding (1), intolerance due to intractable vomiting (1), switch to dabigatran (1), switching to apixaban (1), and hospice (1)), whereas warfarin was discontinued prematurely in 28 patients $(18.30 \%)$ for the following reasons (GI bleeding (15), major bleeding events (4), high risk for bleeding (4), 
TABLE 2: Demographic and clinical characteristics of patients of therapeutic dose group of rivaroxaban compared to warfarin.

\begin{tabular}{|c|c|c|c|}
\hline Patients' characteristics & $\begin{array}{l}\text { Therapeutic dose group of rivaroxaban } \\
\qquad(N=87)\end{array}$ & $\begin{array}{l}\text { Warfarin } \\
(N=153)\end{array}$ & $p$ value \\
\hline Mean age \pm SD & $69.94 \pm 15.24$ & $71.35 \pm 13.09$ & 0.7088 \\
\hline Age $\geq 65$ & $59(67.82 \%)$ & $104(67.97 \%)$ & \multirow{2}{*}{0.98} \\
\hline Age $<65$ & $28(32.18 \%)$ & $49(32.03)$ & \\
\hline \multicolumn{4}{|l|}{ Gender } \\
\hline Female & $39(44.83 \%)$ & $83(54.25 \%)$ & \multirow{2}{*}{0.1605} \\
\hline Male & $48(55.17 \%)$ & $70(45.75 \%)$ & \\
\hline \multicolumn{4}{|l|}{ Ethnic group } \\
\hline White & $66(75.86 \%)$ & $133(86.93 \%)$ & \multirow{3}{*}{0.285} \\
\hline AA & $12(13.79 \%)$ & $4(2.61 \%)$ & \\
\hline Others & $9(10.35 \%)$ & $16(10.46 \%)$ & \\
\hline \multicolumn{4}{|l|}{ Indication for drug } \\
\hline $\mathrm{AF}$ & $67(77.01 \%)$ & $93(60.78 \%)$ & \multirow{4}{*}{$<0.0001^{\dagger}$} \\
\hline VTE treatment & $12(13.79 \%)$ & $56(36.60 \%)$ & \\
\hline VTE prophylaxis & $2(2.30 \%)$ & $2(1.31 \%)$ & \\
\hline Other & $6(6.90 \%)$ & $2(1.31 \%)$ & \\
\hline Mean duration being on drug (Days) \pm SD & $125.30 \pm 131.00$ & $252.95 \pm 167.91$ & $<0.0001^{\dagger}$ \\
\hline Duration $\leq 40$ days & $31(35.63 \%)$ & $16(10.46 \%)$ & $<0.0001^{\dagger}$ \\
\hline Concomitant with aspirin & $44(50.58 \%)$ & $63(41.18 \%)$ & $0.0008^{\dagger}$ \\
\hline Concomitant with thienopyridine & $11(12.64 \%)$ & $27(17.65 \%)$ & 0.3074 \\
\hline Dual antiplatelet agents & $8(9.20 \%)$ & $15(9.80 \%)$ & 0.8776 \\
\hline Concomitant with NSAIDs & $8(9.20 \%)$ & $7(4.58 \%)$ & 0.2187 \\
\hline $\mathrm{Hb}<12$ & $27(32.14 \%)$ & $54(35.29 \%)$ & \multirow{2}{*}{0.0803} \\
\hline Missing data & 3 & 0 & \\
\hline $\mathrm{Cr}>1.5$ & $5(5.95 \%)$ & $15(9.80 \%)$ & \multirow{2}{*}{0.1134} \\
\hline Missing data & 3 & 0 & \\
\hline GFR $\leq 30$ & $1(1.20 \%)$ & $6(3.92 \%)$ & \multirow{2}{*}{0.5645} \\
\hline Missing data & 3 & 0 & \\
\hline $\mathrm{ALT}>40$ & $8(10.26 \%)$ & $28(20 \%)$ & \multirow{2}{*}{0.1081} \\
\hline Missing data & 9 & 13 & \\
\hline \multicolumn{4}{|l|}{ BMI } \\
\hline$<18.5$ & $3(3.45 \%)$ & $0(0 \%)$ & \multirow{4}{*}{0.4152} \\
\hline $18.5-24.9$ & $21(24.14 \%)$ & $35(22.88 \%)$ & \\
\hline$>25$ & $63(72.41 \%)$ & $118(77.12 \%)$ & \\
\hline Missing data & 0 & 0 & \\
\hline Previous GI bleeding & $4(4.60 \%)$ & $15(9.80 \%)$ & 0.1551 \\
\hline
\end{tabular}

AA: African American, AF: atrial fibrillation, ALT: alanine aminotransferase, BMI: body mass index, Cr: creatinine, GFR: glomerular filtration rate, GI: gastrointestinal, $\mathrm{Hb}$ : hemoglobin, NSIADs: nonsteroidal anti-inflammatory drugs, and VTE: venous thromboembolism events. ${ }^{\dagger}$ Signifying statistical significant values.

switching to dabigatran (4), and switching to rivaroxaban (1)).

3.2. GI Bleeding Events (Table 3). GI bleeding occurred in 7 patients $(4.76 \%)$ in the rivaroxaban group when compared to 15 patients $(9.80 \%)$ in the warfarin group ( $p=$ 0.094) (Table 3). All cases of GI bleeding in rivaroxaban group occurred in patients who were on therapeutic doses ( $>10 \mathrm{mg} /$ day). As a result, $8.01 \%$ of patients on therapeutic doses of rivaroxaban developed GI bleeding which was not statistically different from warfarin group $(p=0.65)$. The mean age for GI bleeders in rivaroxaban group was
$72.14 \pm 15.40$ years when compared to $75.80 \pm 11.38$ years in warfarin group $(p=0.4801)$. The mean duration of being on the drug was $29.00 \pm 38.03$ days in rivaroxaban group as compared to $163.87 \pm 143.5$ days in warfarin group $(p=$ 0.0239). Concomitant use of antiplatelet agents or NSAIDs, laboratory parameters, BMI, and prior GI bleeding were not statistically different between GI bleeders in both groups $(p>$ 0.05 in all parameters).

Multivariate analysis carried out using a logistic regression showed that patients who were on rivaroxaban for $\leq 40$ days had a higher incidence of GI bleeding than those who were on the drug for $>40$ days $(\mathrm{OR}=2.8, p=0.023)$. 
TABLE 3: Demographic and clinical characteristics of patients with GI bleeding in both groups.

\begin{tabular}{|c|c|c|c|}
\hline $\begin{array}{l}\text { Characteristics of patients } \\
\text { with GI bleeding }\end{array}$ & $\begin{array}{c}\text { Rivaroxaban } \\
\quad(N=7)\end{array}$ & $\begin{array}{l}\text { Warfarin } \\
(N=15)\end{array}$ & $p$ value \\
\hline GI bleeding events & $7 / 147(4.76 \%)$ & $15(9.80 \%)$ & 0.094 \\
\hline $\begin{array}{l}\text { GI bleeding events with } \\
\text { high dose }\end{array}$ & $7 / 87(8.01 \%)$ & $15(9.80 \%)$ & 0.65 \\
\hline Mean age \pm SD & $72.14 \pm 15.40$ & $75.80 \pm 11.38$ & 0.4801 \\
\hline \multicolumn{4}{|l|}{ Gender } \\
\hline Female & $2(28.57 \%)$ & $7(46.67 \%)$ & \multirow{2}{*}{0.4214} \\
\hline Male & $5(71.43 \%)$ & $8(53.33 \%)$ & \\
\hline \multicolumn{4}{|l|}{ Ethnic group } \\
\hline White & $6(85.71 \%)$ & $13(86.67 \%)$ & \multirow{3}{*}{0.9517} \\
\hline AA & $1(14.29 \%)$ & $1(6.67 \%)$ & \\
\hline Others & 0 & $1(6.67 \%)$ & \\
\hline \multicolumn{4}{|l|}{ Indication for drug } \\
\hline $\mathrm{AF}$ & $5(71.43 \%)$ & $10(66.67 \%)$ & \multirow{4}{*}{0.8233} \\
\hline VTE treatment & $1(14.29 \%)$ & $5(33.33 \%)$ & \\
\hline VTE prophylaxis & $1(14.29 \%)$ & 0 & \\
\hline Other & 0 & 0 & \\
\hline Prophylactic dose & 0 & NA & \\
\hline Therapeutic doses & 7 & NA & \\
\hline $\begin{array}{l}\text { Mean duration being on } \\
\text { drug (days) } \pm \text { SD }\end{array}$ & $29.00 \pm 38.03$ & $163.87 \pm 143.5$ & $0.0239^{\dagger}$ \\
\hline Duration $\leq 40$ days & $5(71.43 \%)$ & $5(33.33 \%)$ & 0.3770 \\
\hline Concomitant with aspirin & $4(57.14 \%)$ & $7(46.67 \%)$ & 0.6471 \\
\hline $\begin{array}{l}\text { Concomitant with } \\
\text { thienopyridine }\end{array}$ & $3(42.86 \%)$ & $4(26.67 \%)$ & 0.4476 \\
\hline Dual antiplatelet agents & $2(28.57 \%)$ & $3(20 \%)$ & 0.655 \\
\hline Concomitant with NSAIDs & $1(14.29 \%)$ & 0 & 0.1341 \\
\hline $\mathrm{Hb}<12$ & $3(42.86 \%)$ & $7(46.67 \%)$ & 0.8673 \\
\hline $\mathrm{Cr}>1.5$ & $1(14.29 \%)$ & $2(13.33 \%)$ & 0.9517 \\
\hline $\mathrm{GFR} \leq 30$ & $0(0 \%)$ & $0(0 \%)$ & NA \\
\hline ALT $>40$ & $1(14.29 \%)$ & $2(13.33 \%)$ & 0.9517 \\
\hline \multicolumn{4}{|l|}{ BMI } \\
\hline$<18.5$ & 0 & $0(0 \%)$ & \multirow{3}{*}{0.899} \\
\hline $18.5-24.9$ & $3(42.86 \%)$ & $6(40 \%)$ & \\
\hline$>25$ & $4(57.14 \%)$ & $9(60 \%)$ & \\
\hline Previous GI bleeding & $2(28.57 \%)$ & $1(6.67 \%)$ & 0.1632 \\
\hline Upper GI tract & $3(42.86 \%)$ & $6(40 \%)$ & 0.899 \\
\hline Lower GI tract & $4(57.14 \%)$ & $5(33.33 \%)$ & 0.29 \\
\hline Occult GI bleeding & $0(0 \%)$ & $4(26.67 \%)$ & 0.1309 \\
\hline $\begin{array}{l}\text { Death related to GI } \\
\text { bleeding }\end{array}$ & $0(0 \%)$ & $0(0 \%)$ & NA \\
\hline
\end{tabular}

AA: African American, AF: atrial fibrillation, ALT: alanine aminotransferase, BMI: body mass index, Cr: creatinine, GFR: glomerular filtration rate, GI: gastrointestinal, Hb: hemoglobin, NSIADs: nonsteroidal anti-inflammatory drugs, and VTE: venous thromboembolism events. ${ }^{\dagger}$ Signifying statistical significant values. 
TABLE 4: Site of GI bleeding.

\begin{tabular}{|c|c|c|c|}
\hline Site of GI bleeding & \multicolumn{3}{|l|}{ Rivaroxaban $(n)$} \\
\hline Upper GI tract & \multicolumn{3}{|c|}{$\begin{array}{l}\text { (a) Distal esophageal ulcer with friable ulcer } \\
\text { (b) Gastric ulcer (1) } \\
\text { (c) Esophageal varices (1) }\end{array}$} \\
\hline Lower GI tract & \multicolumn{3}{|c|}{$\begin{array}{l}\text { (a) Rectal cancer (1) } \\
\text { (b) Internal hemorrhoids (1) } \\
\text { (c) Internal hemorrhoids with diverticulosis } \\
\text { multiple colonic polyps (1) } \\
\text { (d) Sigmoid ulcers (1) }\end{array}$} \\
\hline Occult GI bleeding & \multicolumn{3}{|l|}{ None } \\
\hline \multicolumn{4}{|c|}{$\begin{array}{l}\text { AVM: arteriovenous malformation, EGD: esophagogastroduodenoscopy, E } \\
\text { disease. }{ }^{*} \text { Patient had hematemesis which indicated upper GI bleeding, but } \\
\text { blood per rectum which indicated lower GI bleeding in the clinical scenario, }\end{array}$} \\
\hline \multicolumn{4}{|c|}{ TABLE 5: Secondary aims. } \\
\hline Events & $\begin{array}{l}\text { Rivaroxaban } \\
(N=147)\end{array}$ & $\begin{array}{l}\text { Warfarin } \\
(N=153)\end{array}$ & $p$ value \\
\hline $\begin{array}{l}\text { Major bleeding other } \\
\text { than GI bleeding }\end{array}$ & $6(4.08 \%)$ & $4(2.61 \%)$ & 0.5348 \\
\hline $\mathrm{ICH}$ & $1(0.68 \%)$ & $0(0 \%)$ & 0.4900 \\
\hline Stroke or TIA & $1(0.68 \%)$ & $1(0.65 \%)$ & 1.0000 \\
\hline Symptomatic VTE & $2(1.36 \%)$ & $2(1.31 \%)$ & 1.0000 \\
\hline $\begin{array}{l}\text { ACS that required } \\
\text { interventions }\end{array}$ & $3(2.04 \%)$ & $8(5.23 \%)$ & 0.2189 \\
\hline All-cause death & $2(1.36 \%)$ & $8(5.23 \%)$ & 0.1042 \\
\hline
\end{tabular}

ACS: acute coronary syndrome, ICH: intracranial hemorrhage, TIA: transient ischemic attack, and VTE: venous thromboembolism events.

Concomitant use of dual antiplatelet agents (aspirin and thienopyridine) was associated with an increased risk of GI bleeding in rivaroxaban group ( $\mathrm{OR}=7.4, p=0.0378$ ). A history of prior GI bleeding was a risk factor for GI bleeding in the rivaroxaban group $(\mathrm{OR}=15.5)$. Age, gender, ethnicity, BMI, concomitant use of aspirin (alone), thienopyridines (alone), or NSAIDs, hemoglobin $<12 \mathrm{~g} / \mathrm{dL}$, creatinine $>1.5 \mathrm{mg} / \mathrm{dL}$, GFR $\leq 30 \mathrm{~mL} / \mathrm{min} / 1.73 \mathrm{~m}^{2}$, and alanine aminotransferase $>40 \mathrm{IU} / \mathrm{L}$ were not risk factors. The site of GI bleeding in rivaroxaban group was the lower GI tract in $57.14 \%$ and upper GI tract in $42.86 \%$ when compared to $33.33 \%$ and $40 \%$, respectively, in the warfarin group with $26.67 \%$ without obvious site of GI bleeding $(p>0.05)$. Table 4 shows the site of GI bleeding in both groups. There was no death related to GI bleeding in both groups.

3.3. Secondary Aims (Table 5). Major bleeding events, defined as the bleeding events that required hospitalization and cessation of the anticoagulation agent, occurred in 6 patients $(4.08 \%)$ in rivaroxaban group (hematuria (2), epistaxis (2), ICH (1), and postoperative knee \{surgical site\} bleeding that required reoperation (1)), when compared to 4 patients in warfarin group (retroperitoneal bleeding (2), hemarthrosis $(1)$, and soft tissue bleeding due to valvular carcinoma (1)) $(p=0.5348)$. ACS that required angioplasty with or without
Warfarin $(n)$
(a) PUD (2)
(b) AVM in stomach/duodenum (3)
(c) Sphincterotomy site after ERCP (1)
(d) Scopes were not performed (1)
(a) Colon cancer (2)
(b) Internal hemorrhoids
(c) Large cecal polyp (1)
(d) Scopes were not performed (1)*

EGD/colonoscopy/push enteroscopy were negative (4)


In RECORD 4, there was one case of fatal upper GI bleeding $(0.07 \%)$ who was taking 2 types of NSAIDs and aspirin in rivaroxaban (10 $\mathrm{mg}$ daily) group during the 2-week study period when compared to none in enoxaparin $30 \mathrm{mg}$ BID group [5]. In a pooled analysis of these four trials with a total of 12,729 patients receiving rivaroxaban $(10 \mathrm{mg}$ once daily) or enoxaparin, major GI bleeding occurred in 8 cases of 6183 patients $(0.129 \%)$ on rivaroxaban when compared to one case in the enoxaparin arm $(0.016 \%)$ during the 2 weeks, which comprised all cases of clinically overt extra-surgicalsite bleeding events [26]. In MAGELLAN trial for extended thromboprophylaxis ( $35 \pm 4$ days) with $10 \mathrm{mg}$ once daily dose of rivaroxaban in acutely ill hospitalized medical patients, there was a report of one case of fatal GI bleeding $(0.025 \%)$ in the rivaroxaban group. However, GI bleeding events were not separated from other bleeding events in the published data [8].

As mentioned above, all cases of GI bleeding in our study occurred in patients on the therapeutic doses of rivaroxaban. It has been shown that major and nonmajor bleeding events, including GI bleeding, with rivaroxaban are dose-dependent as demonstrated in the phase II trials $[27,28]$. In ODIXA-hip and ODIXA-knee phase II trials, the incidence of major bleeding events increased from $0.8-$ $1 \%$ with a dose of $2.5 \mathrm{mg} / \mathrm{BID}$ to $5.4-7.5 \%$ with $30 \mathrm{mg} / \mathrm{BID}$ $[27,28]$. There was also a significant dose trend for major bleeding in ODIXA-OD hip study with increased risk of major bleeding from $0.7 \%$ with a $10 \mathrm{mg}$ once daily dose to $5.1 \%$ with $40 \mathrm{mg}$ once daily dose during study period of 610 days [29]. Also, in ATLAS ACS-TIMI 46 dose-escalation phase II trials, the risk of clinically significant bleeding with rivaroxaban increased in a dose-dependent manner (hazard ratio increased from 2.21 with $5 \mathrm{mg}$ dose to 5.06 with $20 \mathrm{mg}$ dose) [9]. In EINSTEIN-DVT and EINSTEIN-PE studies, there was no separation of GI bleeding events from other major or nonmajor bleeding events in published data; however, in EINSTEIN-extension, there were 8 cases (1.34\%) of GI bleeding events that described as clinically relevant nonmajor bleeding, but again there was no separation of major GI bleeding from other major bleeding events $[6,7]$.

Major GI bleeding events were more common in rivaroxaban group when compared to warfarin group in ROCKET AF study (3.15\% versus $2.16 \%$, resp., $p<0.0001)$ [1]. This risk was higher in those with moderate renal impairment (GFR of $30-49 \mathrm{~mL} / \mathrm{min} / 1.73 \mathrm{~m}^{2}$ ) when compared to those with preserved renal function, despite the dose reduction of rivaroxaban to $15 \mathrm{mg}$ once daily instead of $20 \mathrm{mg}$ once daily (4.1\% versus $2.6 \%$, resp., $p=0.02$ ) [30]. In J-ROCKET AF Japanese trial which compared a Japan-specific reduced dose of rivaroxaban $(15 \mathrm{mg}$ once daily instead of $20 \mathrm{mg}$ for those with preserved renal function and $10 \mathrm{mg}$ once daily for those with GFR between 30 and $49 \mathrm{~mL} / \mathrm{min} / 1.73 \mathrm{~m}^{2}$ instead of $15 \mathrm{mg}$ once daily) to warfarin, major GI bleeding events occurred in 8 cases $(1.25 \%)$ in the rivaroxaban group and 15 cases in the warfarin group (2.35\%) [31]. Majority of the bleeding occurred in the upper GI tract (6 cases versus 12 cases in rivaroxaban and warfarin, resp.) [31]. Of those 8 patients in the rivaroxaban group, 5 bleeding events occurred in patients with a preserved renal function when compared to 3 cases with GFR of $30-49 \mathrm{~mL} / \mathrm{min} / 1.73 \mathrm{~m}^{2}$ [32].

The number of GI bleeding events observed in our study was higher than the other studies, which may be attributed, in part, to the difference in the definitions of GI bleeding that was used in our study. We compared the incidence of all GI bleeding that required hospitalization and cessation of the active drug, as opposed to ROCKET AF trial which separated major GI bleeding (which was associated with dropping $\mathrm{Hb}$ by $2 \mathrm{~g} / \mathrm{dL}$ or requiring transfusion of 2 units of blood) from nonmajor bleeding. By using our definition, it is possible that we included all GI bleeding events (major and nonmajor).

In our study, the first 40 days of rivaroxaban use was a risk factor for developing GI bleeding. The odds of GI bleeding for patients on rivaroxaban for $\leq 40$ days were 2.8 times higher than those on the drug for $>40$ days. This is possibly because rivaroxaban may achieve the anticoagulant effect earlier than warfarin. The time in therapeutic range (TTR) for international normalized ratio (INR) for warfarin is low in the first months of starting the drug. For example, in EINSTEIN-DVT trial, the TTR was $54.1 \%$ in the first month when compared to $66.4 \%$ in the tenth month [6]. Rivaroxaban most likely unmasks the preexisting diseases (e.g., colon cancer) during the first 40 days of therapy faster than warfarin. Prior GI bleeding increased the risk of developing GI bleeding with rivaroxaban use by 15.5 times. This effect is again because of the rapid achievement of excellent anticoagulant effect and therefore rivaroxaban may unmask any preexisting GI condition.

The concomitant use of NSAIDs and antiplatelet agents with anticoagulants is important because of the potential increased risk of GI bleeding with their use; however, our study did not show any increased risk of GI bleeding with concomitant use of NSAIDs or aspirin (alone), or thienopyridines (alone). It has been shown that neither NSAIDs nor aspirin has a clinically relevant interaction with rivaroxaban $[33,34]$. In RECORD trials, $72 \%, 9 \%$, and $<1 \%$ of patients used NSIADs (at least once), aspirin, and thienopyridines, respectively, during the study period which resulted in nonsignificant increases in any bleeding events [35]. Our study, however, showed that the concurrent use of dual antiplatelet agents (aspirin and thienopyridine) increased the risk of GI bleeding by 7.4 times. It has been shown that concomitant use of dual antiplatelet agents with anticoagulants, including novel oral anticoagulant agents such as rivaroxaban and dabigatran, increases the risk of major and nonmajor bleeding events including GI bleeding [36].

In our study, age, gender, ethnicity, BMI, hemoglobin of $<12 \mathrm{~g} / \mathrm{dL}$, creatinine $>1.5 \mathrm{mg} / \mathrm{dL}, \mathrm{GFR} \leq 30 \mathrm{~mL} / \mathrm{min} / 1.73 \mathrm{~m}^{2}$, and alanine aminotransferase $>40 \mathrm{IU} / \mathrm{L}$ were not the risk factors for the development of GI bleeding in rivaroxaban group. However, the advanced age, especially the age over 75 , was a risk factor for GI bleeding in patients on rivaroxaban in a recent study [37]. Similar to this study, Chang and his group using a medical and pharmacy administrative database demonstrated that the risk of GI bleeding was not different between rivaroxaban and warfarin which was similar to our study results [38]. The site of GI bleeding in the rivaroxaban 
group in our study was more often in the lower GI tract; however, it was not statistically different between the groups.

This study has several limitations. First, the size of the study was small when compared to other studies in this field. Second, since our study was retrospective, it carries its own bias such as missing information. Third, there was heterogeneity between both the groups such as age and previous GI bleeding which was minimized when only the therapeutic group was compared to the control group (compare Tables 1 and 2); however some other differences such as the indication for the drug continued which may have affected the results. Ideally, homogeneity between the studied group and control group is recommended; it is not always possible or feasible in a retrospective study without affecting the selection bias. The strengths in our study were that it reflects the real-world practice and also is the first study that addresses the risk of GI bleeding as a primary aim.

In conclusion, our study provides data that support the similarity of GI bleeding risks between rivaroxaban and warfarin. Rivaroxaban is more convenient than warfarin for both patients and health care providers. The risk factors for the development of GI bleeding in patients on rivaroxaban were the first 40 days of drug use, concomitant use of dual antiplatelet agents, and a history of previous GI bleeding. Our study is another step toward bid adieu to warfarin.

\section{Disclosure}

This research was presented as a poster at ACG Annual Scientific Meeting in San Diego, California, USA, October 1116 th 2013.

\section{Conflict of Interests}

The authors declare that there is no conflict of interests regarding the study or the publication of this paper.

\section{Authors' Contribution}

Muhammed Sherid contributed to study design, literature review, data collection, data analysis, initial paper writing, paper review, and approval of final version; Salih Samo, Samian Sulaiman, and Husein Husein contributed to study design, literature review, data collection, data analysis, paper review, and approval of final version; Ruth Tupper contributed to the biostatistics, data analysis, paper review, and approval of final version. Charles Spurr, Humberto Sifuentes, and Subbaramiah Sridhar contributed to study design, literature review, data analysis, paper review, and approval of final version. All authors approved the final paper.

\section{References}

[1] M. R. Patel, K. W. Mahaffey, J. Garg et al., "Rivaroxaban versus warfarin in nonvalvular atrial fibrillation," The New England Journal of Medicine, vol. 365, no. 10, pp. 883-891, 2011.

[2] B. I. Eriksson, L. C. Borris, R. J. Friedman et al., "Rivaroxaban versus enoxaparin for thromboprophylaxis after hip arthroplasty," The New England Journal of Medicine, vol. 358, no. 26, pp. 2765-2775, 2008.
[3] A. K. Kakkar, B. Brenner, O. E. Dahl et al., "Extended duration rivaroxaban versus short-term enoxaparin for the prevention of venous thromboembolism after total hip arthroplasty: a doubleblind, randomised controlled trial," The Lancet, vol. 372, no. 9632, pp. 31-39, 2008.

[4] M. R. Lassen, W. Ageno, L. C. Borris et al., "Rivaroxaban versus enoxaparin for thromboprophylaxis after total knee arthroplasty," The New England Journal of Medicine, vol. 358, no. 26, pp. 2776-2786, 2008.

[5] A. G. Turpie, M. R. Lassen, B. L. Davidson et al., "Rivaroxaban versus enoxaparin for thromboprophylaxis after total knee arthroplasty (RECORD4): a randomised trial," The Lancet, vol. 373, no. 9676, pp. 1673-1680, 2009.

[6] R. Bauersachs, S. D. Berkowitz, B. Brenner et al., "Oral rivaroxaban for symptomatic venous thromboembolism," The New England Journal of Medicine, vol. 363, no. 26, pp. 2499-2510, 2010.

[7] H. R. Büller, M. H. Prins, A. W. Lensin et al., "Oral rivaroxaban for the treatment of symptomatic pulmonary embolism," The New England Journal of Medicine, vol. 366, no. 14, pp. 1287-1297, 2012.

[8] A. T. Cohen, T. E. Spiro, H. R. Büller et al., "Rivaroxaban for thromboprophylaxis in acutely ill medical patients," The New England Journal of Medicine, vol. 368, no. 6, pp. 513-523, 2013.

[9] J. Mega, E. Braunwald, S. Mohanavelu et al., "Rivaroxaban versus placebo in patients with acute coronary syndromes (ATLAS ACS-TIMI 46): a randomised, double-blind, phase II trial," The Lancet, vol. 374, no. 9683, pp. 29-38, 2009.

[10] J. L. Mega, E. Braunwald, S. A. Murphy et al., "Rivaroxaban in patients stabilized after a ST-segment elevation myocardial infarction: results from the ATLAS ACS-2-TIMI-51 trial (AntiXa Therapy to Lower Cardiovascular Events in Addition to Standard Therapy in Subjects with Acute Coronary SyndromeThrombolysis In Myocardial Infarction-51)," Journal of the American College of Cardiology, vol. 61, no. 18, pp. 1853-1859, 2013.

[11] E. Perzborn, J. Strassburger, A. Wilmen et al., "In vitro and in vivo studies of the novel antithrombotic agent BAY 59-7939an oral, direct Factor Xa inhibitor," Journal of Thrombosis and Haemostasis, vol. 3, no. 3, pp. 514-521, 2005.

[12] D. Kubitza, M. Becka, B. Voith, M. Zuehlsdorf, and G. Wensing, "Safety, pharmacodynamics, and pharmacokinetics of single doses of BAY 59-7939, an oral, direct factor Xa inhibitor," Clinical Pharmacology and Therapeutics, vol. 78, no. 4, pp. 412421, 2005.

[13] D. Kubitza, M. Becka, G. Wensing, B. Voith, and M. Zuehlsdorf, "Safety, pharmacodynamics, and pharmacokinetics of BAY 59-7939-an oral, direct factor Xa inhibitor-after multiple dosing in healthy male subjects," European Journal of Clinical Pharmacology, vol. 61, no. 12, pp. 873-880, 2005.

[14] X. Zhao, P. Sun, Y. Zhou et al., "Safety, pharmacokinetics and pharmacodynamics of single/multiple doses of the oral, direct Factor Xa inhibitor rivaroxaban in healthy Chinese subjects," British Journal of Clinical Pharmacology, vol. 68, no. 1, pp. 77-88, 2009.

[15] J. Jiang, Y. Hu, J. Zhang et al., "Safety, pharmacokinetics and pharmacodynamics of single doses of rivaroxaban-an oral, direct factor Xa inhibitor-in elderly Chinese subjects," Thrombosis and Haemostasis, vol. 103, no. 1, pp. 234-241, 2010.

[16] W. Mueck, B. I. Eriksson, K. A. Bauer et al., "Population pharmacokinetics and pharmacodynamics of rivaroxaban-an oral, direct factor Xa inhibitor-in patients undergoing major 
orthopaedic surgery," Clinical Pharmacokinetics, vol. 47, no. 3, pp. 203-216, 2008.

[17] M. Gheorghiade, A. Thyssen, R. Zolynas et al., "Pharmacokinetics and pharmacodynamics of rivaroxaban and its effect on biomarkers of hypercoagulability in patients with chronic heart failure," Journal of Heart and Lung Transplantation, vol. 30, no. 2, pp. 218-226, 2011.

[18] C. Weinz, T. Schwarz, D. Kubitza, W. Mueck, and D. Lang, "Metabolism and excretion of rivaroxaban, an oral, direct factor xa inhibitor, in rats, dogs, and humans," Drug Metabolism and Disposition, vol. 37, no. 5, pp. 1056-1064, 2009.

[19] D. Kubitza, M. Becka, W. Mueck et al., "Effects of renal impairment on the pharmacokinetics, pharmacodynamics and safety of rivaroxaban, an oral, direct Factor Xa inhibitor," British Journal of Clinical Pharmacology, vol. 70, no. 5, pp. 703-712, 2010.

[20] D. Kubitza, A. Roth, M. Becka et al., "Effect of hepatic impairment on the pharmacokinetics and pharmacodynamics of a single dose of rivaroxaban - an oral, direct Factor Xa inhibitor," British Journal of Clinical Pharmacology, vol. 76, no. 1, pp. 89-98, 2013.

[21] D. Kubitza, M. Becka, A. Roth, and W. Mueck, "The influence of age and gender on the pharmacokinetics and pharmacodynamics of rivaroxaban - an oral, direct factor Xa inhibitor," Journal of Clinical Pharmacology, vol. 53, no. 3, pp. 249-255, 2013.

[22] D. Kubitz, M. Becka, A. Roth, and W. Mueck, "Dose-escalation study of the pharmacokinetics and pharmacodynamics of rivaroxaban in healthy elderly subjects," Current Medical Research and Opinion, vol. 24, no. 10, pp. 2757-2765, 2008.

[23] M. J. Gnoth, U. Buetehorn, U. Muenster, T. Schwarz, and S. Sandmann, "In vitro and in vivo P-glycoprotein transport characteristics of rivaroxaban," Journal of Pharmacology and Experimental Therapeutics, vol. 338, no. 1, pp. 372-380, 2011.

[24] J. M. Walenga and C. Adiguzel, "Drug and dietary interactions of the new and emerging oral anticoagulants," International Journal of Clinical Practice, vol. 64, no. 7, pp. 956-967, 2010.

[25] W. Mueck, D. Kubitza, and M. Becka, "Co-administration of rivaroxaban with drugs that share its elimination pathways: pharmacokinetic effects in healthy subjects," British Journal of Clinical Pharmacology, vol. 76, no. 3, pp. 455-466, 2013.

[26] A. G. G. Turpie, M. R. Lassen, B. I. Eriksson et al., "Rivaroxaban for the prevention of venous thromboembolism after hip or knee arthroplasty. Pooled analysis of four studies," Thrombosis and Haemostasis, vol. 105, no. 3, pp. 444-453, 2011.

[27] A. G. G. Turpie, W. D. Fisher, K. A. Bauer et al., "BAY 59-7939: an oral, direct factor Xa inhibitor for the prevention of venous thromboembolism in patients after total knee replacement. A phase II dose-ranging study," Journal of Thrombosis and Haemostasis, vol. 3, no. 11, pp. 2479-2486, 2005.

[28] B. I. Eriksson, L. Borris, O. E. Dahl et al., "Oral, direct Factor Xa inhibition with BAY 59-7939 for the prevention of venous thromboembolism after total hip replacement," Journal of Thrombosis and Haemostasis, vol. 4, no. 1, pp. 121-128, 2006.

[29] B. I. Eriksson, L. C. Borris, O. E. Dahl et al., "A once-daily, oral, direct Factor Xa inhibitor, rivaroxaban (BAY 59-7939), for thromboprophylaxis after total hip replacement," Circulation, vol. 114, no. 22, pp. 2374-2381, 2006.

[30] K. A. A. Fox, J. P. Piccini, D. Wojdyla et al., "Prevention of stroke and systemic embolism with rivaroxaban compared with warfarin in patients with non-valvular atrial fibrillation and moderate renal impairment," European Heart Journal, vol. 32, no. 19, pp. 2387-2394, 2011.
[31] M. Hori, M. Matsumoto, N. Tanahashi et al., "Rivaroxaban vs. Warfarin in Japanese patients with atrial fibrillation-the JROCKET AF study," Circulation Journal, vol. 76, no. 9, pp. 21042111, 2012.

[32] M. Hori, M. Matsumoto, N. Tanahashi et al., "Safety and efficacy of adjusted dose of rivaroxaban in Japanese patients with nonvalvular atrial fibrillation-subanalysis of J-ROCKET AF for patients with moderate renal impairment," Circulation Journal, vol. 77, no. 3, pp. 632-638, 2013.

[33] D. Kubitza, M. Becka, W. Mueck, and M. Zuehlsdorf, "Rivaroxaban (BAY 59-7939) - an oral, direct Factor Xa inhibitor-has no clinically relevant interaction with naproxen," British Journal of Clinical Pharmacology, vol. 63, no. 4, pp. 469-476, 2007.

[34] D. Kubitza, M. Becka, W. Mueck, and M. Zuehlsdorf, "Safety, tolerability, pharmacodynamics, and pharmacokinetics of rivaroxaban - an oral, direct factor Xa inhibitor-are not affected by aspirin," Journal of Clinical Pharmacology, vol. 46, no. 9, pp. 981-990, 2006.

[35] B. I. Eriksson, N. Rosencher, R. J. Friedman, M. Homering, and O. E. Dahl, "Concomitant use of medication with antiplatelet effects in patients receiving either rivaroxaban or enoxaparin after total hip or knee arthroplasty," Thrombosis Research, vol. 130, no. 2, pp. 147-151, 2012.

[36] J. Oldgren, L. Wallentin, J. H. Alexander et al., "New oral anticoagulants in addition to single or dual antiplatelet therapy after an acute coronary syndrome: a systematic review and meta-analysis," European Heart Journal, vol. 34, no. 22, pp. 1670-1680, 2013.

[37] N. S. Abraham, S. Singh, G. C. Alexander et al., "Comparative risk of gastrointestinal bleeding with dabigatran, rivaroxaban, and warfarin: population based cohort study," The British Medical Journal, vol. 350, 2015.

[38] H. Y. Chang, M. Zhou, W. Tang, G. C. Alexander, and S. Singh, "Risk of gastrointestinal bleeding associated with oral anticoagulants: population based retrospective cohort study," British Medical Journal, vol. 350, Article ID h1585, 2015. 


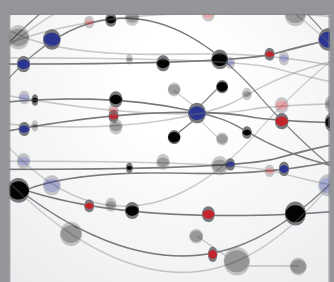

The Scientific World Journal
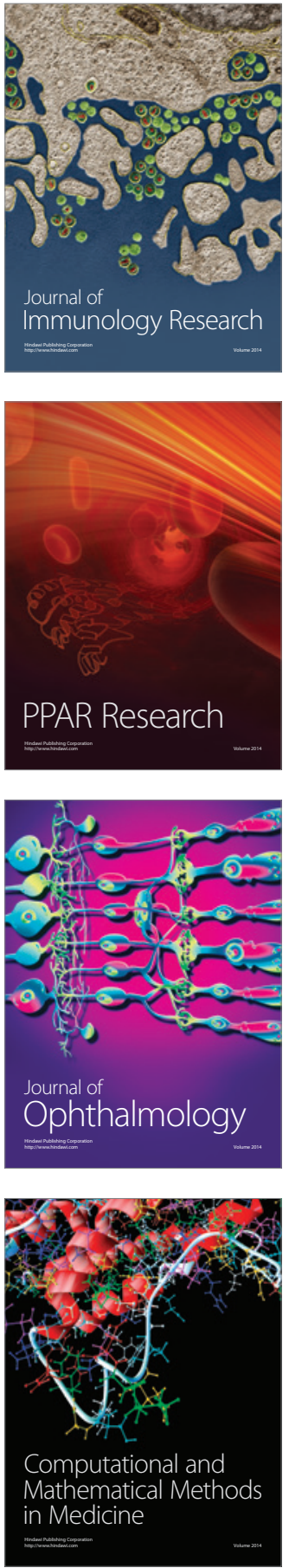

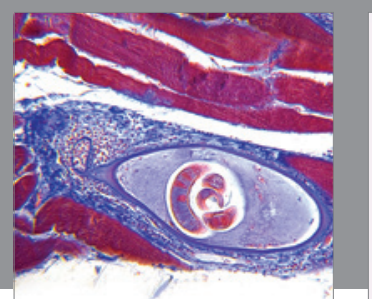

Gastroenterology Research and Practice

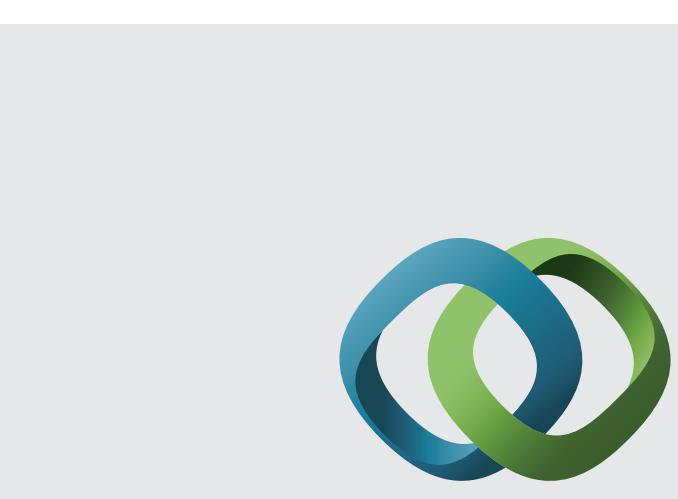

\section{Hindawi}

Submit your manuscripts at

http://www.hindawi.com
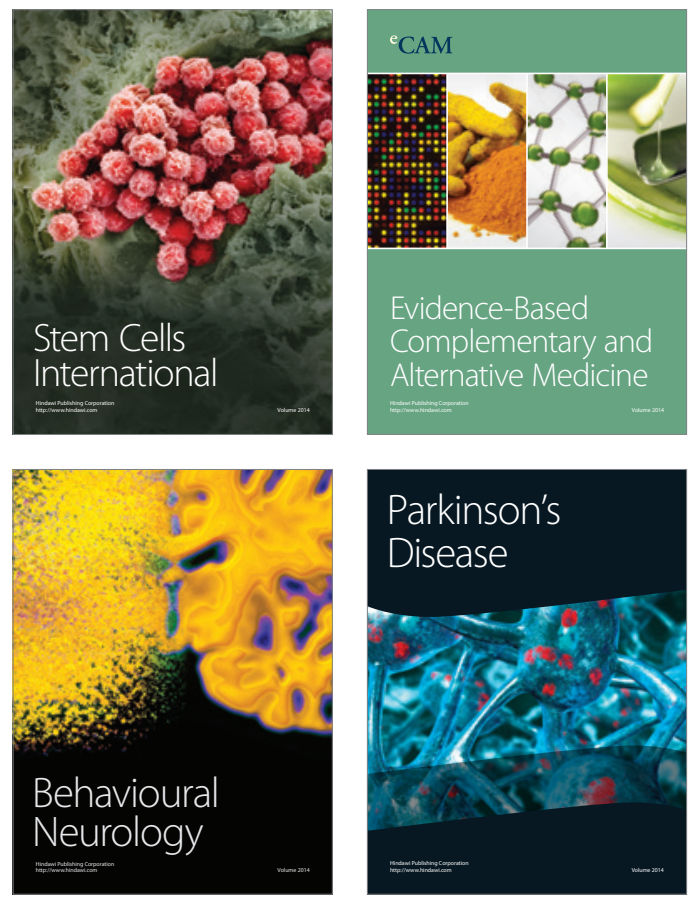
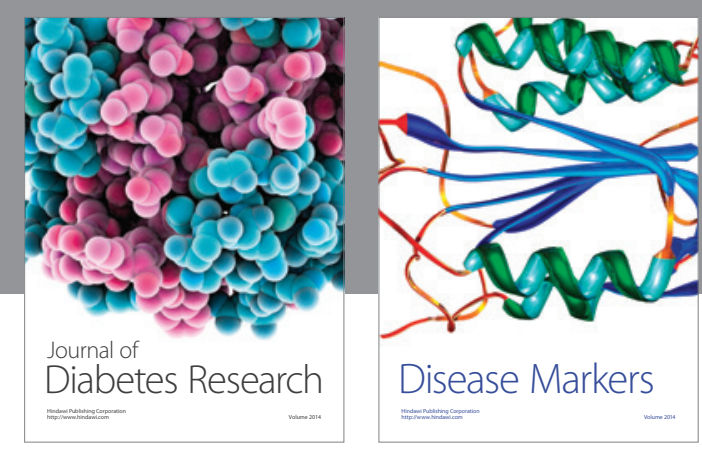

Disease Markers
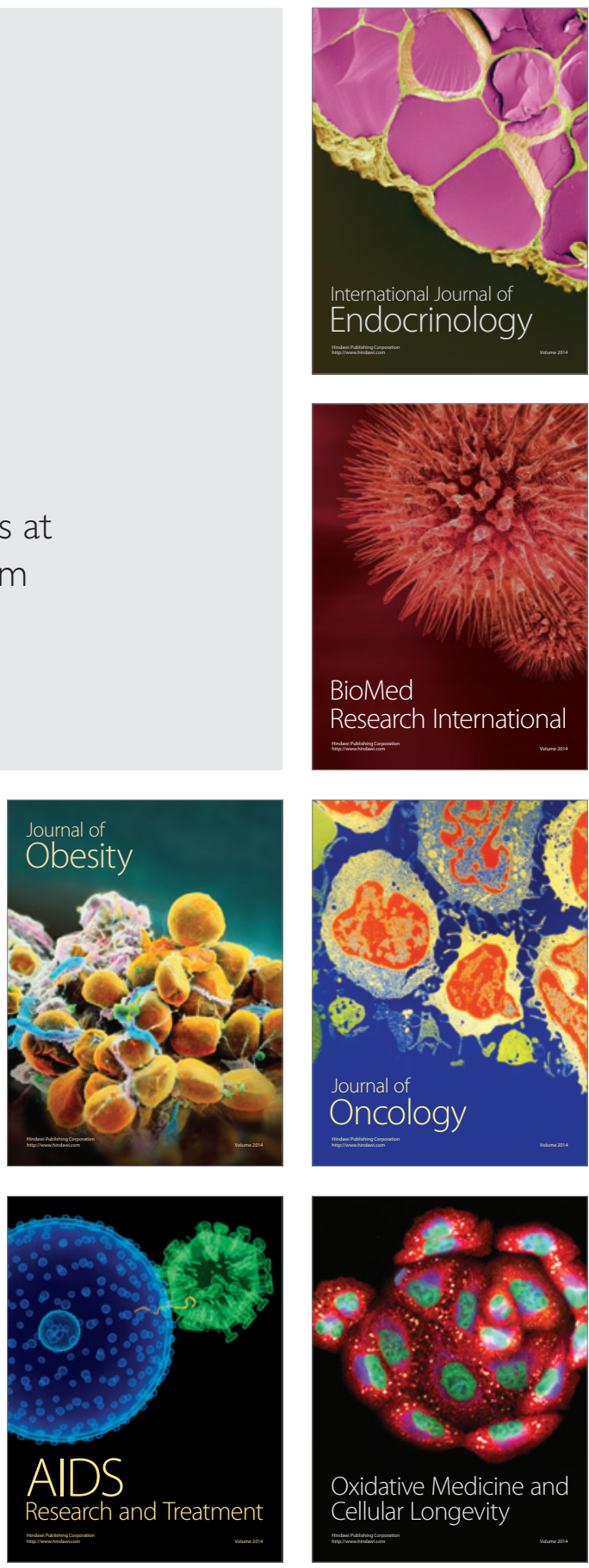